\title{
Review on the Current Status and Countermeasures and Suggestions of Aquatic Products Safety Risk Communication in China
}

\author{
Shengjun CHEN, Laihao LI, Xiangqing YANG, Xiao HU \\ Key Laboratory of Aquatic Product Processing, Ministry of Agriculture; Laboratory of Quality \& Safety \\ Risky Assessment for Aquatic Product on Storage and Preservation (Guangzhou); National R\&D Center for \\ Aquatic Product Processing; South China Sea Fisheries Research Institute, CAFS, Guangzhou 510300, China
}

\begin{abstract}
According to the definition of the Codex Alimentarius Commission(CAC) and the relevant standards, risk communication refers to all stakeholders related to risk, risk factors and risk perception of information and views, including explain the result of the risk assessment and risk management decisions based on interactive communication during the risk analysis in the whole process. The safety risk sources of aquatic products in China were overviewed from environmental pollution, fishery drugs residue, processing and distribution process, as well as import and export trade of aquatic products in the paper. Based on the analysis of the current status in risk communication in China, the countermeasures and suggestions of aquatic products safety risk communication were put forward in order to ensure the safety of aquatic products in China.
\end{abstract}

KEYWORD: aquatic product; risk communication; current status; countermeasures and suggestions

\section{INTRODUCTION}

With the development of the society and the increasing of people's living standard, from the time of deprivation food into how to eat safety, nutrition, health, and keep the Chinese traditional dietary habits of the rich taste of hobby. But, open the newspaper every day, open the TV every day, always appear all kinds of food safety problems of news reports, the media often plaint that food safety is an enormous problem. Therefore, when the food safety problems occurred, even the food safety experts explained, it was hard to remove all of dissatisfaction. In fact, on July 10, 2012, the index of global food safety report, released in 105 countries surveyed showed that the rank food safety of China in the whole world was the 39th, belongs to a better level, showed that the food security situation is relatively good. "China's first One Health research on international forum" held on November 23, 2014, China's food safety expert Chen Junshi academician in the speech said that China's food safety overall qualified rate reached $90 \%$, and the qualified rate in Beijing, Shanghai, Guangzhou reached 95\%[1].

There is no denying that food safety problem is real, on the one hand, related to people health consciousness enhancement; at the same time, the important reason is that the path of the food safety risk communication channels is not so fluent. Risk communication is an important part of risk analysis, according to the definition of the Codex Alimentarius Commission and the relevant standards, risk communication is to point to in the whole process risk analysis, risk assessment, risk managers, consumers, industry, academia, and other stakeholders to risk, risk factors and risk perception of information and views, including explain the result of the risk assessment and risk management decision-making basis for interactive communication [2]. The purpose of risk communication is through public participation, to understand of the problems involved in the process of risk analysis, to make the risk assessment and risk management more scientific and reasonable, fair and transparent on the basis of according to relevant laws and regulations. Therefore, studying to establish a scientific conforms to the situation of aquatic products risk communication mode, choosing appropriate content of communication and exchanges, to promote safety of aquatic products import and export trade were of great significance. As a producer of aquatic products, we work on safety control of aquatic products, discuss the current status as well as the countermeasures and suggestions in order to improve the effectiveness of aquatic products risk communication. 


\section{AQUATIC PRODUCTS ARE AN IMPORTANT SOURCE OF FOOD}

Aquatic products are an important component of agriculture in China, occupy an important place in the national economic development. In 2013, total output of aquatic products reached 61.72 million tons, the national per capita is $45.35 \mathrm{~kg}$ of aquatic products; and export quantity of aquatic products reach 3.96 million tons in 2013, exports of $\$ 20.26$ billion, trade surplus of aquatic products of $\$ 11.63$ billion, aquatic products exports ranked the first of the commodities export[3]. The aquatic products play an important position in the human diet structure, and they are one of the important sources of human proteins, about accounting for $20 \%$ of the human consumption of animal protein. Aquatic products with rich nutrition, taste delicious, nutritional balance good advantage and loved by people, and aquatic products rich in a variety of essential nutrients and trace elements, aquatic products of eicosapentaenoic acid (EPA) and docosahexaenoic acid (DHA) is a kind of polyunsaturated fatty acids, mainly the fat found in fish, are found only in the natural diatoms, red algae and brown algae to synthesize the EPA and DHA.

\section{AQUATIC PRODUCTS SAFETY RISK SOURCES IN CHINA}

Constantly in recent years related to food safety incidents, such as shellfish toxins, angiostrongyliasis cantonensis in snails, and drug residues, the illegal use of additives in aquatic products, caused people concern about food safety, and food safety has become a global issue of common concern. From problems of quality and safety of aquatic products, aquatic products breeding environment, breeding process inputs, processing problems, problems that cause the quality and safety of aquatic products, including illegal drug residues, the illegal use of additives, preservation and shipping process to improper or microbial levels of corruption, etc., have affected the domestic market sales and export trade, harm people's health, affect the sustainable development of aquaculture. The influencing factors of quality security of aquatic products mainly has the following several aspects.

(1) Environmental pollution is aggravating, affect the safety of aquatic products: heavy metal exceeds limit quantity of standards, pesticides, microbial levels of aquatic products, organic pollutants, such as shellfish often find out lead, cadmium, arsenic, tuna in the algae in shellfish mercury levels and microbial overweight, polychlorinated biphenyls (PCBS), overweight, etc[ 4-5].

(2) Fishery drugs residue pollution caused by the aquatic products quality safety problems: farmers in pursuit of the output of aquatic products, prevent fish disease, use high-density breeding and extensive use of all kinds of fishery drugs, feed additives, such as hormones, especially the majority of farmers for the scale of small farmers, the quality and safety of opinion is weak, don't use as stipulated in the national and provincial standards and fishery drugs, does not comply with the requirements of the fishery drugs take medicine period, and even the use of banned drugs, resulting in medicine residual overweight problems of aquatic products, aquatic products safe to eat[6-7].

(3) Caused by the quality and safety of aquatic products processing, circulation process problem: in the processing of aquatic products due to the producers in order to better products in the process of the presentation, longer storage period, abuse of food processing in the production process using chemical additives, such as excessive use of food additives is often happened, such as in the use of formaldehyde as a preservative[8-9].

(4) Source of aquatic products import and export trade: aquatic products import and export trade of agricultural trade internationalization, make a large number of imported seafood controlling Chinese market to the domestic market of aquatic products bring severe challenges, and the export of aquatic products in China, but abroad such as anti-dumping, quality and safety reason to set a large number of non-tariff barriers on the aquatic products export from China[10-11]. All these factors, makes China's aquatic products exports do not comport with greatpower status of aquatic products, and Chinese aquatic product export terminal market tends to be control in the hands of foreign traders, cause Chinese export of aquatic products price fluctuation is enormous, and this is great potential risks in international trade of aquatic products, so it needs to carry out the safety risk assessment in the field.

\section{CURRENT STATUS OF AQUATIC PRODUCTS SAFETY RISK COMMUNICATION IN CHINA}

Provisions of the eighty-second in food safety law of the People's Republic of China: the state established a unified food safety information release system. In the framework of food safety law, the relevant departments to formulate the food safety information management system, such as the measures for the administration of the food safety information released, the information about strengthening the food safety risk management plans, has been clear about the food safety information from the system of reporting system, disposal and release program. But on the whole, China's food safety risk communication is still in its infancy, the lack of communication on both sides of the interaction, at 
the same time to carry out the risk communication needs to improve the technical supporting system of work necessary, for the purpose of risk communication, ways and means to still need to further clarify. On October 13, 2011, the national food safety risk assessment center establishment ceremony held in Beijing[12]. At the same time, the agriculture department formed 65 agricultural product quality safety risk assessment laboratory, in Guangzhou, Shanghai and other places set up 6 laboratory of quality \& safety risky assessment for aquatic product and 2 laboratory of quality \& safety risky assessment for aquatic product on storage and preservation[13].

Risk communication way at present is mainly through the website, publications, media communication control the spread of false statements related to food safety, establish a standardized system of new media. To popular science education of related media practitioners, combined with the corresponding rewards and punishment measures, the formation of professional, scientific, standardized, media propaganda team, to ensure the food safety information source is scientific, professional, accurate. Establishing effective communication mechanism, to ensure accurate, timely information release is now a variety of the development of the information transmission channel, especially the popular of the network, make information passed very quickly. And due to the public tend to avoid risk, make hazard information transmission speed is quick, easy to cause panic. The NGO Monterey Bay Aquarium before 2013 evaluated Chinese tilapia products ratings for the level of red (Avoid) [14], in order to solve this problem, Shanghai Ocean University SEAT in the European Union project team argued that the report errors existing in the arguments and reasoning process was carried out one by one, at the same time provides examples of a batch of research achievements and Monterey Bay Aquarium in the opinion of our offer and after a careful evaluation of evidence, the conclusion from red "Avoid" change to yellow "Good Alternative", and in 2013 the formal release. This is a successful example of the risk communication.

At present, in the field of standards and regulations in our country has made many corresponding measures, but these measures stable cross is also an important way of risk communication. Aquatic products quality supervision and management departments at all levels to strengthen the guidance, a variety of ways on thorough strengthen propaganda, deepen the industry for the understanding of the importance of quality and safety of aquatic products, enhance the sense of urgency of crisis; improve the quality safety consciousness and the demand of the whole society. Adopt flexible approach, in production, management and consumption of each link to establish effective guide incentive mechanism, encouraging producers voluntary to make quality management certification and product quality testing, in accordance with the quality standard of produce quality safety of aquatic products; operator voluntary standard management, the safety and quality of aquatic products sales; strengthening ego to protect consciousness, consumer refused to aquatic products with quality and safety problems.

As the exporter of aquatic products, since China's accession to the WTO, the so-called "green barriers", "technical barriers" of reasons caused our country export aquatic products blocked events occur. Therefore, between the importer and risk communication to our country aquatic products smoothly product also has the vital significance. In recent years, a major exporter of aquatic products in China, the other party to send or voluntarily invited representative in China to visit our country export breeding and processing of aquatic products, check the food processing water, sewage treatment, and aquaculture production environment, etc. Through these ways to make the import aquatic products breeding, processing and production situation in our country, to supervise and inspect the production enterprises, at the same time enhance the importer confidence in China's export of aquatic products. These are very good pathways between countries and also a kind of important food risk communication, enhance mutual trust and understanding. In recent years, our country exports the United States, Canada, European Union and other countries the unqualified reason of aquatic products mainly include: the sensory evaluation, moisture content, without permission of the additive, medicine, packaging integrity, sulfite residue as well as microbiology, through these feedback, and to play a good role in guiding production enterprises.

\section{FOR RISK COMMUNICATION COUNTERMEASURES OF AQUATIC PRODUCTS IN CHINA}

\subsection{Definite risk communication goals to ensure the science of the risk communication}

Aquatic product risk communication, the basic goal is through the risk identification, risk information, inform the public risk situation, guide the public right to know the risk, to avoid the risk of conflict. It contained two main contents: one is the risk information provided and risk education; secondly, the adjustment of idea and behavior change, thus achieve the goal of changing process of risk. From the psychological perspective, risk communication is a risk to interact with audience's psychology, and ultimately to achieve the process of psychological presupposition. Main objects are involved in the 
communication main body status, including gender, age, culture level, occupation and other information. Access to information channels and the contents of the information focus; trust, including the degree of trust in experts and government.

\subsection{Research on risk assessment to accumulate materials of risk communication}

Through science and technology project, commissioned by the business to make research on risk assessment, drive the project entity undertaking the aquatic product risk communication as its task, make full use of its research results in risk communication. So in the aquatic products safety knowledge popularization in our country at the same time, also want to encourage to study the basis of risk communication, finance, project support, the basis of data and data accumulation of risk communication, material preparation for risk communication.

\subsection{Expand approaches of risk communication to ensure effectiveness of risk communication}

Risk communication ways are varied, but had a positive effect, also can have a negative impact, so the choice of risk communication is very important to the effectiveness of communication. Current approaches including authority website, newspaper report, the hotline counseling, to provide the contact way of the relevant experts to the media, even by experts and media non-governmental channels to provide information to the public, social intermediary organizations such as association, using a hearing, online information, organized and so on many kinds of ways of the aquatic products safety knowledge training. Our country related department must actively guide the risk communication, through various information channels to communicate with the public in a timely manner, to ensure the consistency of the channel information, improving the efficiency of risk communication, make false suspicion. The China aquatic products processing and marketing alliance(CAPPMA) released tilapia industry development and risk report every year, and the risk is divided into different levels, in order to give an early warning to the whole tilapia industry[14].

\section{CONCLUSIONS}

As people living standard enhancement, the consumption of aquatic products will continue to improve, how to ensure to provide a safe, aquatic food nutrition, health, how will the aquatic food safety status information and management departments and consumers to communicate, lead producer production in accordance with good operating practices, guide the consumer to carry on the rational consumption, are an important topic in front of the safety management of aquatic products and the researchers. Only by establishing benign circulation of aquatic products safety risk communication mechanism, actively guide people to correctly understanding of safety of aquatic products, aquatic food producers, benign mutual trust relationship between managers and consumers, to ensure the safety of aquatic products.

\section{ACKNOWLEDGMENTS}

This project was supported by Scientific Research Funds for Central Non-profit Institutes, South China Sea Fisheries Research Institute, Chinese Academy of Fishery Sciences (No.2013TS01) and by the earmarked fund for Modern Agro-industry Technology Research System (Grant No. nycytx-49).

\section{REFERENCES}

[1] http://news.xinhuanet.com/yzyd/local/20140630/c_11113 87700.htm.

[2] Chen J S. 2008.Risk Analysis of Food Safety-application Guides for State Food Safety Management Departments. Beijing: People's Medical Press, pp. 54-64.

[3] The fishery bureau of the ministry of agriculture of the People's Republic of China.2014. 2014 Chinese fishery statistical yearbook. Beijing: China agriculture press.

[4] Wang Zeng-huan, Lin Qin, Wang Xu-nuo.2010. Analysis of lead content in marine organism and risk assessment in Daya Bay.South China Fisheries Science, 6(1):54-58.

[5] Wang Zeng-huan, Lin Qin, Li Liu-dong. 2012. Survey and dietary exposure assessment of cadmium in shellfish from South China Sea coast. South China Fisheries Science, 8(5):9-14.

[6] Wang Qun,Song Yi,Ma Bing. 2012. Risk assessment of malachite green in aquatic products. Chinese Fishery Quality and Standards, 2(1):22-26.

[7] Song Hong-bo, WU Guang-hong, Shen Mei-fang.2008. Risk evaluation of enrofloxacin in aquatic products. Fishery Modernization, 35(5):39-42.

[8] Liu Shu-ling. 2007. Study on risk assessment and limit standard of formaldehyde in fishery products. Qingdao: Ocean University of Qingdao.

[9] Wang Ying-ying. 2012. Determination of content of polyphosphate in seafood and risk assessment. Qingdao: Qingdao University.

[10] Huang Yu-rui. 2008. Study of the technical barriers to trade of Chinese eel export to Japanese.Nanchang: Jiangxi University of Finance and Economics.

[11] Liu Chun-E, Lin Hong, Zhou Chong.2014. Analysis of aquatic products quality to export of China from 2011 to 2013.Journal of Food Safety and Quality,5(3),977-984.

[12] http://www.cfsa.net.cn/.

[13] http://www.moa.gov.cn/govpublic/ncpzlaq/201201/t20120 112_2455728.htm.

[14] China aquatic products processing and marketing alliance. http://www.cappma.org/. 